\title{
Assessing Social and Emotional Competencies of Undergraduates: A Cross-Cultural Study
}

\author{
Sukhminder Kaur ${ }^{*}$ iD, Thomas Ayana ${ }^{2}$ and Harmilan Kaur ${ }^{1}$ \\ ${ }^{1}$ Department of Psychology, Punjabi University, Patiala, Punjab-147002, India \\ ${ }^{2}$ Department of Behavioral Sciences, College of Education \& Behavioral Sciences, Wollega University, Nekemte, Ethiopia \\ "sukhminder_bhattal@yahoo.co.in (Corresponding Author)
}

\section{ARTICLE INFORMATION}

Received: December 30, 2020

Revised: March 22, 2021

Accepted: April 01, 2021

Published Online: September 29, 2021

\section{Keywords:}

Social-emotional competencies, Culture,

Young adulthood

DOI: $10.15415 /$ iie.2021.92007

\begin{abstract}
The study was conducted to assess social-emotional competencies among Indian and Ethiopian undergraduates. A total of 400 (200 each) participants, with an equal number of 100 male and female were selected through a multi-stage sampling procedure from Punjabi University (India), and Wollega University and Ambo University (Ethiopia). The participants were tested with the Social Skills Inventory (SSI: Riggio \& Carney, 2003), which consists of two super-dimensions, i.e. emotional competence and social competence each having three sub-dimensions: emotional expressivity, emotional sensitivity, emotional control, and social expressivity, social sensitivity and social control respectively. Obtained data were subjected to t-statistics. Significant mean differences in social-emotional competence were observed between the Indian and Ethiopian young adults;male and female samples of the two countries. The Indian sample was greater in Social-emotional competence than the Ethiopian sample. Similarly, male and female participants from the Indian sample were greater in social-emotional skills than that of the Ethiopian sample, except for emotional sensitivity with the female participants, where the mean difference was non-significant. Further explorations are recommended to consolidate or refute the result of the present study.
\end{abstract}

\section{Introduction}

Young adulthood comes up with opportunities to take new responsibilities in social and professional arenas. People at this stage of life need to establish and maintain positive relationships, solve challenging situations in life and adapt to the fast-changing world. Most present-day emerging adults pursue tertiary education and training to broaden their employment opportunities and enjoy an improved quality of life. It has also been justified that the emerging adults need to pass a long time in schools to qualify for the demands of their community; as the global economy transforms from industrialized to an informationbased economy, which requires adequate skills and competencies (Wood et al., 2018). Social-emotional skills play an important role in making adjustments with this state of affairs and also influence many important life outcomes. Social competence, socialemotional competence, social skills, and socialemotional skills have been used interchangeably, representing the ability to convey one's social and emotional messages, effectively receive that of others and exercise emotional and social regulation. Riggio and Carney (2003) equate social competence with social intelligence, the ability to engage in adaptive and positive social interactions (Riggio \& Carney, 2003). Based on Riggio and Carney's conceptualizations, social-emotional skills could be understood as the manifestation of social-emotional competence, implying that a competent individual is skilled in receiving, decoding, and accurately interpreting emotional and social information from both the self and others, and is skilled in sending and regulating emotional and social information appropriate to the interpersonal and situational circumstances. Individuals with such skills are found as resourceful, able to work well with others and take personal and collective responsibility (Jones, Greenberg \& Crowley, 2015). These characteristics are the hallmark of a wellfunctioning society as well as determine the future success of the person. Therefore, the study is aimed at assessing social and emotional competencies among Indian and Ethiopian undergraduates. In addition, the 
trust of the study is to assess if cross-cultural variation exists in social-emotional competencies among young adults belonging to India and Ethiopia by forwarding the following objectives. The study further aimed at testing Riggio and Carney's (2003) basic social-emotional competencies on the data to be collected from both India and Ethiopia.

\section{Objectives}

- To assess social-emotional competencies among Indian and Ethiopian undergraduates.

- To investigate if gender difference exists in terms of social-emotional competencies among undergraduates from the two countries.

\section{Review of Literature}

It has been consistently argued that socialemotional skills are paramount at any stage of development. The development and maintenance of social-emotional competence attributed to different factors are seemingly bound to culture. A cross-cultural analysis shows that social-emotional competence was investigated for a long time and showed some degree of consistency across cultures during the formative years. For instance, a multinational analysis involving preschoolers from eight countries (i.e. Austria, Brazil, Canada, China, Italy, Japan, Russia, and the United States) revealed that social competence is relatively stable across age and countries and gender differences were also observed (LaFreniere et al., 2002). Evidence regarding cross-cultural analysis of social-emotional competence is limited to the formative years of human development.

Evidence shows that social-emotional competence seems consistent across cultures during the formative years; studies revealed increased cross-cultural variation with increasing age (LaFreniere et al., 2002; Chen et al., 2015). The way each culture presents itself to its members is likely to differ across cultures, because of the differential demands from each culture. In addition, the social environment within a broad culture plays a part in the development and maintenance of social-emotional skills. Different theoretical explanations have justified the role of the social environment in the development of socialemotional competencies. For example, Erikson stated that social-emotional competence is developed out of the individuals continuing interaction with the social environment, with the ultimate goal of attaining ego strength or becoming a psychologically healthy individual (Ma, 2012). Vygotsky in his Socio-cultural theory of development also emphasized the role of the social environment in the zone of proximal development (ZPD) through scaffolding (Blunden \& Schmolze, 2004). Vygotsky claimed that children's cognitive enterprises are similar to that of mature adults, and they develop social-emotional skills and related competencies through imitation.

Ecological system's theory of Bronfenbrenner observed the development of social-emotional competence vis-a-vis the relative ecological systems in which the child develops. Within the microsystem, social competence develops out of the bidirectional influences between the child, family, neighborhood, and school that heavily impact the foundation of social development (Ettekal \& Mahoney, 2017). Throughout the individual's developmental trajectories, the mesosystem, exosystem, and macrosystem come into play their respective roles on the individual's subsequent social development (Krishnan, 2010). Healthy neighborhood; communication and collaboration among families and schools; sound economic, social, and cultural practices and policies, and macro-level political and economic stability have been reportedly supporting the development of social-emotional competencies. Albert Bandura is well-known for the notion of triadic reciprocal determinism between the individual (self), behavior and environment. Bandura also proposed three types of influence on socialemotional competence: the behaviors that children and adolescents observe within their home or culture; cognitive variables such as students' expectations of success, and social factors such as classroom and school climate (Huitt \& Dawson, 2011).

Literature reveals that the two countries share some common attributes; for instance, they are found within the broader developing economy of the world, with some specific differences. Analysis was made to compare the two countries using Geert Hofstede's five-dimensional model of cultural orientation (Tamas, 2007; DeMooij \& Hofstede, 2010), which ranks the world countries in terms of power distance index, individualism-collectivism, masculinityfemininity, uncertainty avoidance index, and long term orientation index. Power distance concerns the 
level of equality in wealth and power; high scores indicate inequality in access to power and wealth, and India (77) is greater than Ethiopia (64) in this regard. Individualism-collectivism refers to the degree of the bond between individuals in a particular culture; high scores on individualism indicate loose ties between individuals in the society; everyone is expected to look after themselves and their immediate family. Collectivism is the opposite of individualism; referring to the society where there are strong ties between individuals. Based on this measure, Indian society with an intermediate score (48) represents both collectivistic and individualist traits and Ethiopia (27) is considered as a collectivistic society. Masculinity-femininity index focuses on the degree to which masculine values like competitiveness and the acquisition of wealth are valued over feminine values like relationship building and the quality of life. India and Ethiopia scored 56 and 41 respectively. Uncertainty avoidance index focuses on the level of tolerance for uncertainty and ambiguity with society. A high uncertainty avoidance ranking indicates the country has a low tolerance for uncertainty and ambiguity. This creates a ruleoriented society that institutes laws, rules, regulations, and controls to reduce the amount of uncertainty. A low uncertainty avoidance ranking indicates that the country has less concern about ambiguity and uncertainty and has more tolerance for diversity of opinions. Accordingly, Ethiopia (52) is greater than India (40) on the specific culture variable. Long-term orientation focuses on the degree to which the society embraces, or does not embrace, long-term devotion to traditional values. A high long-term orientation score shows that the country values long-term commitments and tradition, with long-term rewards predicted as a result of today's efforts. India (65) is greater in long-term orientation than Ethiopia (25). Following the bipolar dimension of individualismcollectivism (Hofstede's, model of cultural orientation Indian culture is inclinedtowards collectivism (Jha \& Singh, 2011). Indian people are characterized as status-conscious, power and prestige-oriented, emotional and personalized in relationships (Sinha, 1990). These characteristics hold more importance than individualistic traits. At the same time, many researchers characterize Indians as both collectivist and individualists (Sinha \& Tripathi, 1994; Verma, 2001). Ethiopia, on the other hand, is a collectivist society that prioritizes relationships, group obligations and interpersonal harmony (Baar \& Vissenberg, 2019). Collectivism and emotional intelligence have been proven to be positively associated in studies because in collectivist cultures, people learn to control and limit their emotions to maintain harmonious relationships (Bhullar, Schutte \& Malouff, 2012; Gunkel, Schlagel \& Engle, 2014); whereas individualistic cultures promote self-expression because they do not anticipate others to understand their minds in interpersonal relationships (Markus \& Kitayama, 1991). Bhullar et al., (2012) argue that collectivistic orientation encourages individuals to understand others' emotions and behave appropriately in social settings. Keeping in view the previous studies on cultural characteristics and their association with emotional intelligence, the present study was intended to assess the social skills during emerging adulthood. Apart from the abovementioned cultural variables, no study has been attempted to investigate the cross-cultural differences in social-emotional skills of young people between the two countries. Hence, the present study is aimed to lay a foundation for future research in the area. As far as the knowledge of the researchers extends, social-emotional competency has not been assessed by considering representatives from India and Ethiopia. As a result, this research is critical in paving the way for future investigations from various perspectives. Accordingly, the hypothesized comparison in socialemotional competency between the two countries is mainly based on Girt Hofstede's comparison of cultural orientation and Riggio and Carney's background study on the universality in social-emotional competencies and the apparent gender differences.

\section{Hypotheses}

Based on the review of literature, the following hypotheses were formulated.

$\mathrm{H}_{1}$ : Indian students would be higher on socialemotional competencies as compared to Ethiopian students.

$\mathrm{H}_{2}$ : Male undergraduates from India would be higher on social-emotional competencies than male undergraduates from Ethiopia.

$\mathrm{H}_{3}$ : Female undergraduates from India would be higher on social-emotional competencies than male undergraduates from Ethiopia. 


\section{Method}

\section{Participants}

A total of 400 participants were randomly selected for the study. A total of 200 participants were included from Punjabi University, Patiala, India, and 200 were from two Ethiopian Public Universities: Wollega University and Ambo University. To increase the representativeness of the participants, the study first checked the homogeneity of the participants for the general population of the two countries. This was done by first analyzing the demographic composition of the students from their respective universities. Eventually, academic units and departments were clustered out and the representative sample was selected using the lottery method. Equal number of participants with respect to gender, 100 each for both countries, were selected through multi-stage sampling procedures. The age ranges between 18 and 26 years for the Indian sample, with a mean and standard deviation of 20.87 and 1.76 respectively. The age for the Ethiopian sample ranges between 18 and 27 years, with a mean value of 21.46 and a standard deviation of 1.70 .

\section{Measure}

Social Skills Inventory (Riggio and Carney, 2003) was used together with one demographic item requiring participants to indicate their gender. Social Skills Inventory included 90 items with scale anchors ranging between 1 (Not at all like me) and 5 (Exactly like me). Both the composite scores of the inventory and its six additive sub-scales, i.e. Emotional Sensitivity, Emotional Expressivity, Emotional Control, and Social Sensitivity, Social Expressivity, and Social Control, with each scale constituting 15 items were included in the study. It is a self-administered inventory; in which participants were clearly instructed to fill it themselves. The original study reported Cronbach's alpha reliabilities of the six scales ranging between 0.64 and 0.89 ; whereas, in the current study, the internal consistency of measures was in the range of 0.63 to 0.74 .

\section{Procedure}

A multi-stage sampling technique was employed to recruit participants from the selected colleges and universities. Using the already existing strata of academic units and departments, and the simple random sampling procedure was used to select the students from each of the departments. Prior consent was taken from the concerning authorities of the colleges and departments to approach the students for the selection of the sample. Before administration of the measure, a rapport was built with the participants and they were provided with the appropriate conditions to respond to the questionnaires. The data collection for both samples was conducted in a group setting. The Ethiopian participants were tested as follows:

Participants from each department were tested as one group; with sample size ranging between 18 to 30 students as the number of students of each department differs. The participants were ensured that the information would be kept confidential and only used for research purposes. Then the questionnaire/test booklet containing a total of 91 items (i.e. one item for demographic information and 90 items for social skills were distributed among the participants.

To proceed with each session, instructions were given as follows: "Dear students, the data collection aims to seek information about your gender and social-emotional skills. After filling your sex, proceed to the next part that contains 90 items with a scale ranging between 1 and 5; i.e. 1 stands for "not at all like me", 2 for "a little like me", 3 for "like me", 4 for "very much like me", and 5 for "exactly like me". You fill your sex by putting a tick $(\sqrt{ })$ mark in the box in front of the choices for gender. After you fill your sex, go to the Social Skills Inventory, and try to carefully fill your responses under the choice that you think clearly describes you. You are thankfully allowed to give the filled test back after you complete".

Similarly, the participants from Indian universities were selected and tested in the following manner. Before the administration of the measure, a rapport was built with the participants and they were provided with the appropriate conditions to respond to the questionnaire. Each group consisted of 30-40 participants. The questionnaire was administered by providing the following instruction: "Now, here is a questionnaire with one item asking for your gender and 90 items asking for social-emotional skills which include the skills you use in your daily life. Read the statements carefully, and answer them honestly. There is no time limit but try to complete it as early as possible". The questionnaires were scored as per the guidelines provided in the manual and the obtained scores were subjected to statistical analysis using the latest SPSS Statistical Package for the Social Sciences software. 


\section{Results and Discussion}

The purpose of this study was to assess if there was a significant mean difference in social-emotional competencies between undergraduates from Indian and Ethiopian public universities. Accordingly, data concerning the participants' gender and their socialemotional competencies were collected and subjected to an independent sample t-test (see Tables 1, $2 \& 3$ ). The tables show independent samples t-test statistics comparing the overall sample of the two countries, males and females from the two countries respectively.

Table 1 shows that there is a significant mean difference in social-emotional competencies between India $(\mathrm{M}=278.03, \mathrm{SD}=22.93)$ and Ethiopia $(\mathrm{M}=254.21, \mathrm{SD}=21.55) ; \mathrm{t}(398)=10.58$, $\mathrm{p}=0.000$. The magnitude of the differences in the means (mean difference: $(95 \% \mathrm{CI}=-13.60$ to 27.34) was larger (eta squared $=.219$ ). On average, social-emotional competence was greater for the Indian sample than for the Ethiopian sample. Similarly, significant mean differences are observed between the two groups for emotional competence and social competence, implying that the Indian sample is greater in emotional competence and social competence than the Ethiopian sample (Table 1). In addition, similar findings were observed for the six dimensions of social-emotional competence, emotional expressivity, emotional sensitivity, emotional control, social expressivity, social sensitivity, and social control. On average, the Indian sample is greater in emotional expressivity, emotional sensitivity, emotional control, social expressivity, social sensitivity, and social control than the Ethiopian sample (see Table 1). The result supported the hypothesis, i.e. "Indian students would be higher on social-emotional competencies as compared to Ethiopian students."

Table 1: Means, SDs and t-values for social-emotional competence and its dimensions bycountry, $N=400$ (India $=200$, Ethiopia $=200$ ).

\begin{tabular}{|c|c|c|c|c|c|c|}
\hline Variables & Country & Means & SD & t-values & Sig. (2-tailed) & eta-squared \\
\hline \multirow{2}{*}{$\begin{array}{l}\text { Social-emotional } \\
\text { Competence }\end{array}$} & India & 278.03 & 22.93 & \multirow{2}{*}{10.585} & \multirow{2}{*}{.000} & \multirow[t]{2}{*}{0.219} \\
\hline & Ethiopia & 254.21 & 21.55 & & & \\
\hline \multirow{2}{*}{$\begin{array}{l}\text { Emotional } \\
\text { Expressivity }\end{array}$} & India & 44.94 & 5.90 & \multirow{2}{*}{34.84} & \multirow{2}{*}{.000} & \multirow[t]{2}{*}{0.751} \\
\hline & Ethiopia & 24.73 & 5.67 & & & \\
\hline \multirow{2}{*}{$\begin{array}{l}\text { Emotional } \\
\text { Sensitivity }\end{array}$} & India & 47.07 & 7.69 & \multirow{2}{*}{4.60} & \multirow{2}{*}{.000} & \multirow[t]{2}{*}{0.005} \\
\hline & Ethiopia & 43.31 & 8.60 & & & \\
\hline \multirow{2}{*}{$\begin{array}{l}\text { Emotional } \\
\text { Control }\end{array}$} & India & 44.82 & 6.90 & \multirow{2}{*}{38.27} & \multirow{2}{*}{.000} & \multirow[t]{2}{*}{0.785} \\
\hline & Ethiopia & 21.49 & 5.18 & & & \\
\hline \multirow{2}{*}{$\begin{array}{l}\text { Emotional } \\
\text { Competence }\end{array}$} & India & 136.83 & 12.44 & \multirow{2}{*}{47.87} & \multirow{2}{*}{.000} & \multirow[b]{2}{*}{0.852} \\
\hline & Ethiopia & 89.36 & 6.22 & & & \\
\hline \multirow{2}{*}{ Social Expressivity } & India & 46.20 & 7.95 & \multirow{2}{*}{8.04} & \multirow{2}{*}{.000} & \multirow[t]{2}{*}{0.139} \\
\hline & Ethiopia & 39.88 & 7.71 & & & \\
\hline \multirow{2}{*}{ Social Sensitivity } & India & 47.12 & 7.93 & \multirow{2}{*}{13.33} & \multirow{2}{*}{.000} & \multirow[t]{2}{*}{0.307} \\
\hline & Ethiopia & 36.53 & 7.93 & & & \\
\hline \multirow{2}{*}{ Social Control } & India & 47.88 & 8.35 & \multirow{2}{*}{20.77} & \multirow{2}{*}{.000} & \multirow[t]{2}{*}{0.125} \\
\hline & Ethiopia & 31.46 & 7.39 & & & \\
\hline \multirow{2}{*}{$\begin{array}{l}\text { Social } \\
\text { Competence }\end{array}$} & India & 141.20 & 13.95 & \multirow{2}{*}{26.75} & \multirow{2}{*}{.000} & \multirow[t]{2}{*}{0.683} \\
\hline & Ethiopia & 108.22 & 10.17 & & & \\
\hline
\end{tabular}

${ }^{*} P<.0 .001$, et-squared is the measure of effect size $(0.01=$ small effect, $0.06=$ moderate effect, $0.14=$ large effect; Pallant, 2011$)$.

Table 2 shows that there is significant mean difference in social-emotional competencies between the Indian male sample $(M=280.98, S D=19.69)$ and the
Ethiopia male sample $(\mathrm{M}=253.84, \mathrm{SD}=20.18)$; $\mathrm{t}(198)=9.55, \mathrm{p}=0.000$. The magnitude of the differences in the means (mean difference: $(95 \% \mathrm{CI}$ 
$=21.54$ to 32.75 ) was larger (eta squared $=.315$ ). On average, the social-emotional skill was greater for the Indian male sample than the Ethiopian male sample. In the same vein, significant mean differences were observed between the two groups for emotional competence and social competence dimensions of social-emotional skills, implying that the Indian male sample is greater in emotional competence and social competence than the Ethiopian male sample.
In addition, a similar finding was observed for the six dimensions, i.e. the Indian male sample is greater in emotional expressivity, emotional sensitivity, emotional control, social expressivity, social sensitivity, and social control than the Ethiopian male sample (Table 2). The results supported the hypothesis, i.e. "Male undergraduates from India and Ethiopia would be higher on Social-emotional Competence than male graduates from Ethiopia."

Table 2: Means, SDs and t-values for social-emotional competence and its dimensions of male undergraduates, $\mathrm{N}=200$ (India $=100$, Ethiopia $=100)$.

\begin{tabular}{|c|c|c|c|c|c|c|}
\hline Variables & Country & Mean & Std. Deviation & t-values & Sig. (2-tailed) & eta-squared \\
\hline \multirow{2}{*}{$\begin{array}{l}\text { Social-emotional } \\
\text { competence }\end{array}$} & India & 280.98 & 19.69 & \multirow{2}{*}{9.55} & \multirow{2}{*}{.000} & \multirow{2}{*}{0.315} \\
\hline & Ethiopia & 253.84 & 20.18 & & & \\
\hline \multirow{2}{*}{$\begin{array}{l}\text { Emotional } \\
\text { Expressivity }\end{array}$} & India & 45.45 & 5.72 & \multirow{2}{*}{25.09} & \multirow{2}{*}{.000} & \multirow{2}{*}{0.761} \\
\hline & Ethiopia & 25.65 & 5.43 & & & \\
\hline \multirow{2}{*}{$\begin{array}{l}\text { Emotional } \\
\text { Sensitivity }\end{array}$} & India & 47.60 & 7.56 & \multirow{2}{*}{5.14} & \multirow{2}{*}{.000} & \multirow{2}{*}{0.118} \\
\hline & Ethiopia & 41.86 & 8.15 & & & \\
\hline \multirow{2}{*}{$\begin{array}{l}\text { Emotional } \\
\text { Control }\end{array}$} & India & 45.17 & 6.41 & \multirow{2}{*}{28.30} & \multirow{2}{*}{.000} & \multirow{2}{*}{0.802} \\
\hline & Ethiopia & 22.51 & 4.79 & & & \\
\hline \multirow{2}{*}{$\begin{array}{l}\text { Emotional } \\
\text { Competence }\end{array}$} & India & 138.22 & 12.10 & \multirow{2}{*}{35.51} & \multirow{2}{*}{.000} & \multirow{2}{*}{0.864} \\
\hline & Ethiopia & 89.85 & 6.00 & & & \\
\hline \multirow{2}{*}{ Social Expressivity } & India & 47.16 & 6.68 & \multirow{2}{*}{7.06} & \multirow{2}{*}{.000} & \multirow{2}{*}{0.201} \\
\hline & Ethiopia & 40.26 & 7.09 & & & \\
\hline \multirow{2}{*}{ Social Sensitivity } & India & 47.40 & 7.04 & \multirow{2}{*}{11.75} & \multirow{2}{*}{.000} & \multirow{2}{*}{0.411} \\
\hline & Ethiopia & 35.38 & 7.38 & & & \\
\hline \multirow{2}{*}{ Social Control } & India & 48.20 & 6.66 & \multirow{2}{*}{15.69} & \multirow{2}{*}{.000} & \multirow{2}{*}{0.554} \\
\hline & Ethiopia & 32.92 & 7.08 & & & \\
\hline \multirow{2}{*}{$\begin{array}{l}\text { Social } \\
\text { Competence }\end{array}$} & India & 142.76 & 11.10 & \multirow{2}{*}{22.49} & \multirow{2}{*}{.000} & \multirow{2}{*}{0.719} \\
\hline & Ethiopia & 108.82 & 10.07 & & & \\
\hline
\end{tabular}

${ }^{*} P<.0 .001$, et-squared is the measure of effect size $(0.01=$ small effect, $0.06=$ moderate effect, $0.14=$ large effect; Pallant, 2011)

Table 3 shows that there is significant mean difference in social-emotional competencies between Indian female sample $(\mathrm{M}=275.07, \mathrm{SD}=25.53)$ and the Ethiopian female sample $(M=254.60, S D=22.96)$; $\mathrm{t}(198)=5.87, \mathrm{p}=0.000$. The magnitude of the differences in the means (mean difference: $(95 \% \mathrm{CI}$ $=13.00$ to 27.34 ) was larger (eta squared $=.148$ ). On average, the social-emotional skill was greater for the Indian sample than for the Ethiopian sample. Similarly, significant mean differences were observed between the two groups for emotional competence and social competence, implying that the Indian sample is greater in emotional competence and social competence than the Ethiopian sample (Table 1). The significant mean difference was observed in emotional expressivity, emotional control, social expressivity, social sensitivity, and social control. This indicates that female participants from India were greater on the six dimensions of social-emotional competence. The mean difference for emotional sensitivity was non-significant, implying that female undergraduates from India and Ethiopia do not differ significantly in emotional sensitivity. The result supported the hypothesis, i.e. "Female undergraduates from India wouldbe higher on Social-emotional Competence of female undergraduates from Ethiopia", except for emotional sensitivity. 
Apart from providing support to the hypotheses, the findings of the present study are consistent with the previous cross-cultural studies involving samples from both developed and under developed as well as from different cultural orientations (LaFreniere et al., 2002; Chen et al., 2015). The Indian sample exceeded in socialemotional competence, which might be attributed to cultural differences in both the Hoftsede's cultural orientation (Tamas, 2007; DeMooij \& Hofstede, 2010) and specific child-rearing practices as proposed by the different theories in developmental psychology. For instance, the fact that India is relatively greater in individualism and long-term orientation might have influenced the child-rearing practices in the particular country to have a comparatively better social-emotional competence than the Ethiopian sample. In addition, Vygotsky's social-cultural developmental theory (Blunden \& Schmolze, 2004) and Bronfenbrener's ecological system's theory (Ettekal \& Mahoney, 2017) might have implicated the cultural differences in childrearing practices between the two countries.

Specifically, the result reveals that the Indian sample is greater than the Ethiopian sample on emotional competence and social competence, and their sub-dimensions, except for emotional sensitivity in which the two samples did not differ significantly. The findings can be discussed within the framework of the contextual - developmental perspective which acknowledges the association of cultural values with social functioning (Chen \& French, 2008). Different cultures value social initiative and self-control as the two main dimensions of socio-emotional functioning differently. Indian culture promotes interdependence and cooperation. It is pertinent to note that parents in the family are the primary agent who transfers the cultural values to their wards. Researchers argue that cultural values and beliefs directly manifest in child-rearing practices and parental attitudes. The above-mentioned broad and specific socio-cultural variations might have played a role in placing differences between the two samples. On the other hand, emotional sensitivity seems to have universality across cross-cultural contexts; however, further exploration is needed to validate or refute the particular result.

The findings of this study have significant implications for researchers, teachers, parents, and policymakers. In past studies, it is shown that parents and teachers play a significant role in the promotion of social skills through advice, coaching, and modeling (Ladd, 2005; Lollis, Ross \& Tate, 1992; Tomlin, 2007). So guidance and counseling programs can be organized for Ethiopian parents for making them aware of their role in preparing their wards to act competently in the globalized world. In addition to this, using more systematically planned and implemented socialemotional learning programs during early childhood can benefit in fostering the social competencies of young adults. Despite the significant findings, the present research has some limitations also. Firstly, due to regional differences in countries, it is difficult to conclude that the sample from both countries was representative of Ethiopian and Indian cultures. According to Matsumoto \& Juang (2008), sampling equivalence has been found as the major problem in cross-cultural research. Secondly, the present study used a limited sample size to compare the two countries; had it been a large-scale nationally representative sample, the results might have been different. Nonetheless, the study would be a valuable reference to initiate further cross-cultural exploration across the world and further test the observed difference between the two countries. Further research should be conducted using large-scalenationally representative samples from culturally diverse nations to develop a theoretical and conceptual model that can be used for interventions with particular competence.

\section{References}

Baar, P., \& Vissenberg, C. (2019). Perspectives of students, parents, and teachers on social-emotional learning in Afar, Ethiopia. Utrecht: Utrecht University.

Bhullar, N., Schutte, N., \& Malouff, J. (2012). Associations of individualistic-collectivistic orientations with emotional intelligence, mental health, and satisfaction with life: A tale of two countries. Individual Differences Research, 10(3), 165-175.

Blunden, A., \& Schmolze, N. (2004). Mind and Society. L. S. Vygotsky. USA: Harvard University Press.

Chen, C., Squires, J., Kay, H., Bian, X., Chen, C., Filgueiras, A., Xie, H., Murphy, K., Dolata, J. K., \& Landeira-Fernández, J. (2015). Cross Cultural Gender Differences in Social-emotional Competence of Young Children: Comparisons with Brazil, China, South Korea, and the United States. Mental health in family medicine, 11. https://doi.org/10.25149/17568358.1102009 
Chen, X., \& French, D. C. (2008). Children's social competence in cultural context. Annual Review of Psychology, 59, 591-616. https://doi.org/10.1146/ annurev.psych.59.103006.093606

De Mooij, M., \& Hofstede, G. (2010). The Hofstede Model: Applications to Global Branding and Advertising Strategy and Research. International Journal of Advertising, 29(1), 85-110. https://doi.org/10.2501/ S026504870920104X

Ettekal, A. V., \& Mahoney, J. L. (2017). Ecological Systems Theory. In K. Peppler, The Sage Encyclopedia of Outof-School learning (pp. 2-7). Thousand oaks: Sage Publications, Inc.

Gunkel, M., Schlagel, C., \& Engle, R. (2014). Culture's influence on emotional intelligence: An empirical study of nine countries. Journal of International Management, 20(2), 256-274. https://doi. org/10.1016/j.intman.2013.10.002

Huitt, W., \& Dawson, C. (2011, April). Social development: Why it is important and how to impact it. Educational Psychology Interactive. Valdosta, GA: Valdosta State University. Retrieved from http://www. edpsycinteractive.org/papers/socdev.pdf

Jha, S. D., \& Singh, K. (2011). An analysis of individualismcollectivism across Northern India. Journal of Indian Academy of Applied Psychology, 37(1), 149-156.

Jones, D. E., Greenberg, M., \& Crowley, M. (2015). Early social-emotional functioning and public health: The relationship between kindergarten social competence and future wellness. American Journal of Public Health, 105(11), 2283-2290. https://doi.org/10.2105/ AJPH.2015.302630

Krishnan, V. (2010). Early child development: A Conceptual model. Early childhood council annual conference, "Valuing Care", (pp. 1-17). Christ church Convention Centre, Christchurch, New Zealand: Early Child Mapping Project Alberta.

LaFreniere, P., Masataka, N., Butovskaya, M., Chen, Q., Dessen, M. A., Atwanger, K., Frigerio, A. (2002). Cross-Cultural Analysis of Social Competence and Behavior Problems in Preschoolers. Early Education and Development, 13(2), 201-220. https://doi. org/10.1207/s15566935eed1302_6

Ladd, G. W. (2005). Children's peer relations and social competence: a century of progress. New Haven, CT: Yale University Press.
Lollis, S. P., Tate, E., \& Ross, H. S. (1992). Parents' regulation of their children's peer interactions: Direct influences. In R. Parke \& G. W. Ladd (Eds.), The family and peer relationships, 255-281. Hillsdale, NJ: Erlbaum.

Ma, H. K. (2012). Social-emotional skills as a positive youth development construct: A Conceptual review. The Scientific World Journal, 2012, 1-7. https://doi. org/10.1100/2012/287472

Markus, H., \& Ktayama, S. (1991). Culture and self: Implications for cognition, emotion, and motivation. Psychological Review, 98, 224-253. https://doi. org/10.1037/0033-295X.98.2.224

Matsumoto, D., \& Juang, L. (2008). Culture and psychology ( $4^{\text {th }}$ ed.). San Francisco, CA: Thomson.

Riggio, R. E., \& Carney, D. R. (2003). Social Skills Inventory manual $\left(2^{\text {nd }}\right.$ ed. $)$. Published by Mind Garden, Inc: www.mindgarden.com.

Sinha, J. B. P. (1990). Work culture in the Indian context. New Delhi: Sage.

Sinha, D., \& Tripathi, R. C. (1994). Individualism in a collectivist culture: A case of coexistence of opposites. In U. Kim, H. C., Triandis, C., Kagitcibasi, S. C. Choi, \& G.Yoon (Eds.). Individualism and collectivism: Theory, method, and applications ( $p$. 123-36). Thousand Oaks, CA. Sage

Tamas, A. (2007). Geert Hofstede's Dimensions of Culture: An Inter-cultural Organization Development Tool. www.tamas.com.

Tomlin, A. M. (2007). Parent-provider relationships in early care settings. In O. N. Saracho, \& B. Spoek (Eds.), Contemporary perspectives on social learning in early childhood education, 149-172. Charlotte, NC: Information Age Publishing.

Verma, J. (2001). Situational preference for different types of individualism collectivism. Psychology and Developing Societies, 13, 221-241.

Wood, D., Crapnell, T., Lau, L., Benett, A., Lotstein, D., Ferns, M., \& Kuo A. (2018). Emerging Adulthood as a Critical Stage in the Life Course. In: Halfon N., Forrest C., Lerner R., Faustman E. (eds) Handbook of Life Course Health Development. Springer, Cham. https://doi.org/10.1007/978-3-319-47143-3_7 


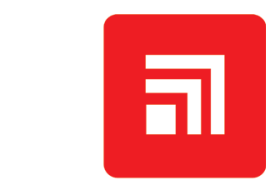

CHITKARA

\section{Issues and Ideas in Education}

Chitkara University, Saraswati Kendra, SCO 160-161, Sector 9-C, Chandigarh, 160009, India

Volume 9, Issue 1

September 2021

ISSN 2320-7655

Copyright: [C 2021 Sukhminder Kaur et al.] This is an Open Access article published in Issues and Ideas in Education (Issues Ideas Educ.) by Chitkara University Publications. It is published with a Creative Commons Attribution- CC-BY 4.0 International License. This license permits unrestricted use, distribution, and reproduction in any medium, provided the original author and source are credited. 